\title{
Dynamic Low Voltage Ride through Detection and Mitigation in Brushless Doubly Fed Induction Generators
}

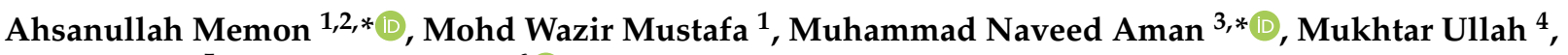 \\ Tariq Kamal ${ }^{5}$ and Abdul Hafeez ${ }^{6}$ (D)
}

1 School of Electrical Engineering, Faculty of Engineering, University Teknologi Malaysia, Skudai 81310, Johor, Malaysia; wazir@utm.my

2 Department of Electrical Engineering, Mehran University of Electrical \& Technology, SZAB Campus, Khairpur Mir 66020, Sindh, Pakistan

3 School of Computing, National University of Singapore, Singapore 117417, Singapore

4 Department of Electrical Engineering, National University of Computer and Emerging Sciences, Islamabad 44000, Islamabad Capital Territory, Pakistan; mukhtar.ullah@nu.edu.pk

5 Department of Computer Systems Engineering, University of Engineering and Technology Peshawar, Peshawar 25000, Khyber Pakhtunkhwa, Pakistan; tkamal@uetpeshawar.edu.pk

6 Computer Science \& Information Technology, University of Engineering and Technology Peshawar, Jalozai Campus, Peshawar 25120, Khyber Pakhtunkhwa, Pakistan; abdul.hafeez@uetpeshawar.edu.pk

* Correspondence: memon.ahsanullah@graduate.utm.my (A.M.); naveed@comp.nus.edu.sg (M.N.A.)

check for updates

Citation: Memon, A.; Mustafa, M.W.; Aman, M.N.; Ullah, M.; Kamal, T.; Hafeez, A. Dynamic Low Voltage Ride through Detection and Mitigation in Brushless Doubly Fed Induction Generators. Energies 2021, 14, 4461. https://doi.org/10.3390/ en14154461

Academic Editors: Andrea Bonfiglio and Andrea Mazza

Received: 29 May 2021

Accepted: 21 July 2021

Published: 23 July 2021

Publisher's Note: MDPI stays neutral with regard to jurisdictional claims in published maps and institutional affiliations.

Copyright: (c) 2021 by the authors. Licensee MDPI, Basel, Switzerland. This article is an open access article distributed under the terms and conditions of the Creative Commons Attribution (CC BY) license (https:/ / creativecommons.org/licenses/by/ $4.0 /)$.

\begin{abstract}
Brushless doubly-fed induction generators have higher reliability, making them an attractive choice for not only offshore applications but also for remote locations. These machines are composed of two back-to-back voltage source converters: the grid side converter and the rotor side converter. The rotor side converter is typically used for reactive current control of the power winding using the control winding current. A low voltage ride through (LVRT) fault is detected using a hysterisis comparison of the power winding voltage. This approach leads to two problems, firstly, the use of only voltage to detect faults results in erroneous or slow response, and secondly, sub-optimal control of voltage drop because of static reference values for reactive current compensation. This paper solves these problems by using an analytical model of the voltage drop caused by a short circuit. Moreover, using a fuzzy logic controller, the proposed technique employs the voltage frequency in addition to the power winding voltage magnitude to detect LVRT conditions. The analytical model helps in reducing the power winding voltage drop while the fuzzy logic controller leads to better and faster detection of faults, leading to an overall faster response of the system. Simulations in Matlab/Simulink show that the proposed technique can reduce the voltage drop by up to 0.12 p.u. and result in significantly lower transients in the power winding voltage as compared to existing techniques.
\end{abstract}

Keywords: low voltage ride through; reactive power control; short-circuit faults; wind energy

\section{Introduction}

Renewable energy systems are gaining traction in mainstream power generation as a result of their environmental friendliness and a growing global demand for energy. Wind energy generation systems with variable speeds and constant frequencies have grown in popularity over the last decade, owing to their increased aerodynamic range, which results in increased efficiency [1], for example, the Doubly-Fed Induction Generator. However, current wind energy generation systems, such as doubly-fed induction generators, employ a brush gear, making deployment and maintenance in remote locations, such as offshore applications, difficult. As the name implies, the brushless doubly-fed induction generator does not contain the brush gear, which results in increased reliability [2]. Additionally, a brushless doubly-fed induction generator has a simpler structure (without a slip gear) and a lower cost than an equivalent doubly-fed induction generator. As a result, brushless 
doubly-fed induction generators have recently attracted the attention of a large number of researchers and industrial applications.

Two distinct sets of three-phase stator windings comprise a brushless doubly-fed induction generator. The first stator winding connected directly to the grid is referred to as the power winding, and it is responsible for generating power. The second stator winding, referred to as the control winding, is connected to the grid indirectly via a fractionally rated Variable Voltage, Variable Frequency converter. To avoid direct coupling, the two stator windings have different pole pair numbers and are coupled via the rotor [3]. The brushless doubly-fed induction generator control strategy is designed to keep the machine connected to the grid during fault conditions leading to low voltages [4,5], i.e., improving the low voltage ride through (LVRT) capability of the machine. To address this issue, this paper focuses on detecting a fault early on and turning on the machine's compensation mode. To this point, the proposed work explores the steady state component of the voltage drop at the PCC and based on the mathematical model, the reference value for reactive current compensation is deduced.

Existing techniques on improving the LVRT capability of brushless doubly-fed induction generators can be categorized as hardware based or control based. Hardware based techniques typically rely on a crowbar to act as a high-value impedance circuit, protecting the machine during faults [6-8]. Although, a crowbar has shown to successfully protect the generator from surge currents during faults, hardware based approaches lead to losses [9], electromagnetic torque oscillations [10], and increase in operation and maintenance costs in addition to the initial hardware cost. Therefore, this paper focuses on proposing a control based solution to the LVRT problem in a brushless doubly-fed induction generator. Existing studies on improving LVRT capability of brushless doubly-fed induction generators using control techniques include the following. Shao et al. [11,12] introduced an LVRT scheme for symmetric and asymmetric voltage dips based on fixed reference values for control winding active and reactive current using an analytical model. The authors detect a LVRT situation using hysteresis comparison of the power winding voltage. A similar approach was proposed in [13]. The authors in [11,12] propose the use of positive and negative sequence currents for LVRT. In another work [14], the authors proposed the use of flux linkages and electromotive force to detect LVRT and a vector control scheme to protect the machine from control winding current peaks. Other works include [15-19], however, all these techniques share two major problems: the detection of LVRT is based on power winding voltage only which results in slow response and the LVRT capability is provided by using fixed reference values for control winding current. A summary of a comparison of the existing techniques for brushless doubly-fed induction generator control and the proposed technique is shown in Table 1.

Table 1. Summary of existing brushless doubly-fed induction generator control techniques.

\begin{tabular}{|c|c|c|c|c|c|c|c|c|}
\hline Feature & [8] & [7] & [6] & [14] & [12] & [13] & [20] & Proposed \\
\hline $\begin{array}{c}\text { DC-link Control } \\
\text { Crowbarless Design } \\
\text { PCC Voltage Drop Reduction } \\
\text { Dynamic Reference values } \\
\text { Fault Detection }\end{array}$ & $\begin{array}{l}\boldsymbol{\bullet} \\
\boldsymbol{\otimes} \\
\boldsymbol{\otimes} \\
\boldsymbol{\otimes} \\
\boldsymbol{\otimes}\end{array}$ & $\begin{array}{l}\boldsymbol{\otimes} \\
\boldsymbol{\otimes} \\
\boldsymbol{\otimes} \\
\boldsymbol{\otimes} \\
\boldsymbol{\otimes}\end{array}$ & $\begin{array}{l}\boldsymbol{\otimes} \\
\boldsymbol{\otimes} \\
\boldsymbol{\otimes} \\
\boldsymbol{\otimes} \\
\boldsymbol{\otimes}\end{array}$ & $\begin{array}{l}0 \\
0 \\
\boldsymbol{0} \\
\boldsymbol{0} \\
\boldsymbol{0}\end{array}$ & $\begin{array}{l}\boldsymbol{\otimes} \\
\boldsymbol{0} \\
\boldsymbol{\otimes} \\
\boldsymbol{\otimes} \\
\boldsymbol{\otimes}\end{array}$ & $\begin{array}{l}\boldsymbol{\theta} \\
\boldsymbol{0} \\
\boldsymbol{\otimes} \\
\boldsymbol{0} \\
\boldsymbol{0}\end{array}$ & $\begin{array}{l}\boldsymbol{\bullet} \\
\boldsymbol{0} \\
\boldsymbol{0} \\
\boldsymbol{\theta} \\
\boldsymbol{\theta}\end{array}$ & $\begin{array}{l}0 \\
0 \\
0 \\
0 \\
0\end{array}$ \\
\hline \multicolumn{9}{|c|}{$\begin{array}{l}\text { - DC-link Control: Can the technique perform DC-link voltage control? } \\
\text { - Crowbarless Design: The technique does not require a crowbar? } \\
\text { - PCC Voltage Drop Reduction: Does the technique reduce the voltage drop at the PCC? } \\
\text { - Dynamic Reference Value: Does the technique use dynamic reference values for control winding current? } \\
\text { - Fault Detection: Does the technique provide fault detection (other than hysteresis comparison)? }\end{array}$} \\
\hline
\end{tabular}

To improve the rotor side converter's response to a fault, this paper proposes the use of fuzzy logic. Modeling complex non-linear systems using traditional control or advance optimization techniques is not only analytically challenging but also results in 
higher computational complexity which might not be suitable for real-time applications. On the other hand, fuzzy logic controllers have shown to perform well in many control applications; these controllers can be used to model and optimize complex and non-linear systems with significantly lower computational complexity [21]. Therefore, this paper proposes a fuzzy logic controller to detect faults. Moreover, most existing techniques only use power winding voltage to detect faults. However, this approach may not only lead to slow response but may also result in false alarms during transient conditions. This paper combines power winding voltage magnitude and frequency to not only reduce the response time to a fault but also to improve the detection accuracy. The proposed fuzzy logic controller is used to detect a short circuit and to take a proactive approach by activating the rotor side converter compensation mode prior to the voltage drop becoming too low and the machine being disconnected. In contrast to machine learning techniques, fuzzy logic allows for the inclusion of subjective knowledge in the form of the rule base. Thus, the proposed fuzzy logic controller gives us the flexibility and convenience of designing the knowledge base according to the generalized behavior of a machine during various faults which results in better robustness [22].

To solve the second problem identified above, i.e., use of fixed control winding current reference values for reactive current control, in this paper, the reference value for reactive current compensation is analyzed using an analytical model of the voltage drop at the point of common coupling (PCC) in the event of a short-circuit fault. The brushless doubly-fed induction generator's equivalent circuit is used to analyze the load's reactive current steady state and transient state components. This leads to a dynamic reference value for the control winding current obtained from the load current. Thus, the purpose of this paper is to develop an rotor side converter control scheme for a brushless doubly-fed induction generator that will reduce the voltage drop and improve the LVRT characteristics during faults. The major contributions of this paper are as follows:

1. The equivalent circuit of a brushless doubly-fed induction generator is used to develop an analytical model of the voltage drop at the PCC in the presence of a short circuit fault. The effect of the reactive current reference value on the PCC voltage drop (as seen from the rotor side converter in the event of a short-circuit fault) is then analyzed using the analytical model.

2. Insights gained from the analytical model of a brushless doubly-fed induction generator in the presence of a short circuit fault are used to propose a rotor side converter reactive current control scheme to minimize the voltage drop at the PCC. This is done by analyzing the effect of using the load current value as a reference to minimize the overall voltage drop magnitude at the PCC. To the best of the authors' knowledge, this is the first work on using an analytical model of the voltage drop to design the rotor side converter controller.

3. To improve the rotor side converter's response to faults and reduce the latency of detecting the onset of a fault, a fuzzy logic controller is proposed with voltage magnitude and frequency (at the power winding) used as the two inputs. The proposed fuzzy logic controller is then used to turn on the rotor side converter's compensation mode if a fault is detected. To the best of the authors' knowledge, this is the first work on using voltage magnitude and frequency to detect faults using a fuzzy logic controller.

The rest of the paper is organized as follows: Section 2 presents the system model considered in this paper. Section 3 presents the proposed technique. The results are discussed in Section 4. Finally, the paper conclusion is presented in Section 5.

\section{System Model}

The system model considered in this paper is shown in Figure 1. A brushless doublyfed induction generator consists of two stator windings, i.e., stator power winding and stator control winding. The rotor winding of the brushless doubly-fed induction generator couples the two stator windings. The stator power winding is connected to a three-phase resistive-inductive load as well as to the grid (viz a transformer). The stator control winding 
is composed of two back-to-back voltage source converters, i.e., the rotor side converter and grid side converter. The two converters are connected through DC-link, where the capacitor allows for an independent design of controller for the rotor side converter and grid side converter, respectively. The grid side converter is connected to the stator power winding at the point of common coupling. A capacitor bank $C_{g}$ is used to reduce stator power winding voltage ripples and filter out harmonics produced by the grid side converter. The equivalent load resistance and inductance are represented by $R_{L}$ and $L_{L}$, respectively. The set of notations used in this paper is given in Table 2.

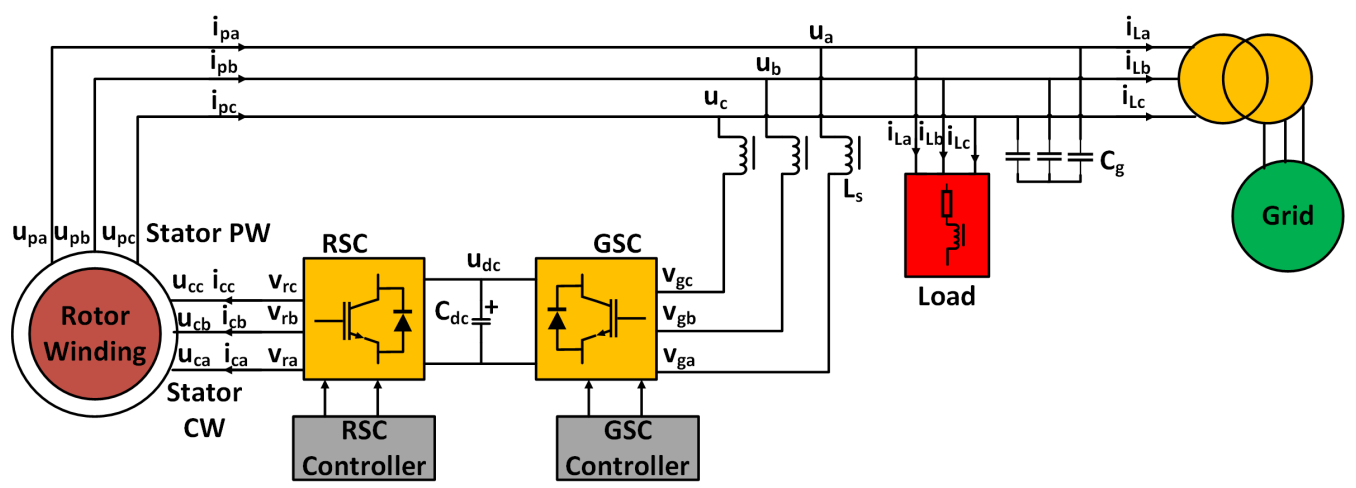

Figure 1. System model.

Table 2. Table of notations.

\begin{tabular}{ll}
\hline Notation & Description \\
\hline PCC & Point of common coupling \\
LVRT & Low voltage ride through \\
$\omega_{p}, \omega_{c}, \omega_{r}$ & Speeds of stator power winding, control winding, and Rotor \\
\hline$\omega_{n}$ & Natural frequency \\
\hline$u_{p a}, u_{p b}, u_{p c}$ & Three phase stator power winding voltage \\
\hline$u_{c a}, u_{c b}, u_{c c}$ & Three phase stator control winding voltage \\
\hline$u_{a}, u_{b}, u_{c}$ & Three phase stator power winding voltage at PCC \\
\hline$u_{d c}$ & DC-link voltage \\
\hline$v_{r a}, v_{r b}, v_{r c}$ & Three phase rotor side converter voltage \\
\hline$v_{g a}, v_{g b}, v_{g c}$ & Three phase grid side converter voltage \\
\hline$i_{p a}, i_{p b}, i_{p c}$ & Three phase stator power winding current \\
\hline$i_{c a}, i_{c b}, i_{c c}$ & Three phase stator control winding current \\
\hline$i_{L a}, i_{L b}, i_{L c}$ & Three phase load current \\
\hline$i_{T a}, i_{T b}, i_{T c}$ & Three phase grid current \\
\hline$C_{d c}$ & DC-link capacitor \\
\hline$C_{g}$ & capacitor bank \\
\hline$L_{s}, L_{L}$ & Filter, load inductance \\
\hline$R_{s}, R_{L}$ & Internal, load resistance \\
\hline$R_{p}, R_{c}, R_{r}$ & Stator power winding, control winding, and rotor resistance \\
\hline$L_{p}, L_{c}, L_{r}$ & Magnetizing inductance of rotor to power winding/control winding \\
\hline$L_{r p}, L_{r c}$ & \\
\hline
\end{tabular}


The stator power winding and stator control winding produce $p_{p}$ and $p_{c}$ pole-pairs rotating at speeds of $\omega_{p}$ and $\omega_{c}$, respectively. Consequently, the rotor winding produces induced current with angular speeds [23]:

$$
\begin{aligned}
& \omega_{r p}=\omega_{p}-p_{p} \omega_{r} \\
& \omega_{r c}=\omega_{c}-p_{c} \omega_{r} .
\end{aligned}
$$

As $\omega_{r p}=-\omega_{r c}$, the rotor speed is given by:

$$
\omega_{r}=\frac{\omega_{p}+\omega_{c}}{p_{p}+p_{c}} .
$$

Thus, the operation principal of brushless doubly-fed induction generator is to keep $\omega_{p}$ constant by controlling $\omega_{c}$ in response to varying $\omega_{r}$.

Typically, the grid side converter maintains a constant DC link voltage; the standard grid side converter controller based on scalar control is used in Figure 1 [24]. In this paper, we focus on the rotor side converter for reactive current control to reduce the voltage drop at the PCC and improve the LVRT characteristics of the brushless doubly-fed induction generator. The following assumptions are made:

1. The rotor side converter and grid side converter are decoupled using the capacitance

$C_{d c}$, therefore, the analysis for them can be done independently $[25,26]$.

2. The grid line impedance is negligible under normal conditions [27].

3. The proposed technique is focused on reducing the voltage drop magnitude and not the voltage distortion during a fault. Therefore, the transient component of load current which is responsible for voltage distortion is ignored [20].

\section{Proposed Technique}

The per-phase steady-state equivalent circuit of a brushless doubly-fed induction generator is shown in Figure 2.

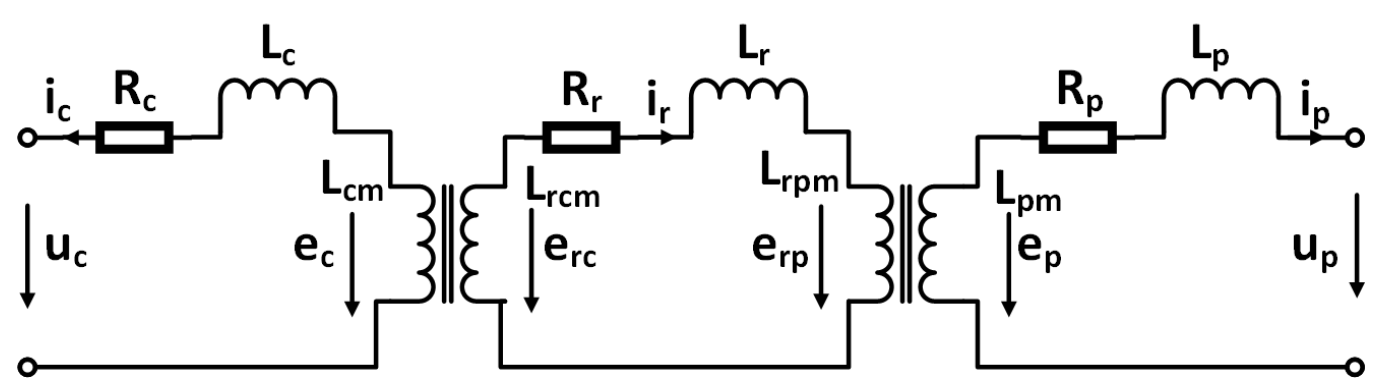

Figure 2. Brushless doubly-fed induction generator equivalent circuit.

To analyze the situation of LVRT during a short circuit fault, the single-phase equivalent circuit for the stand-alone brushless doubly-fed induction generator system seen from the control winding side is shown in Figure 3 . In Figure $3, i_{L a}$ is the a-phase load current, and $i_{s}$ represents the short circuit fault current. $u_{a}$ and $i_{a}$ are the voltage and current for the a-phase at the PCC. Denoting the amplitude and angular frequency of the phase voltage by $U_{m}$ and $\omega$, respectively, we can obtain $e_{c a}$ as follows [20]. 


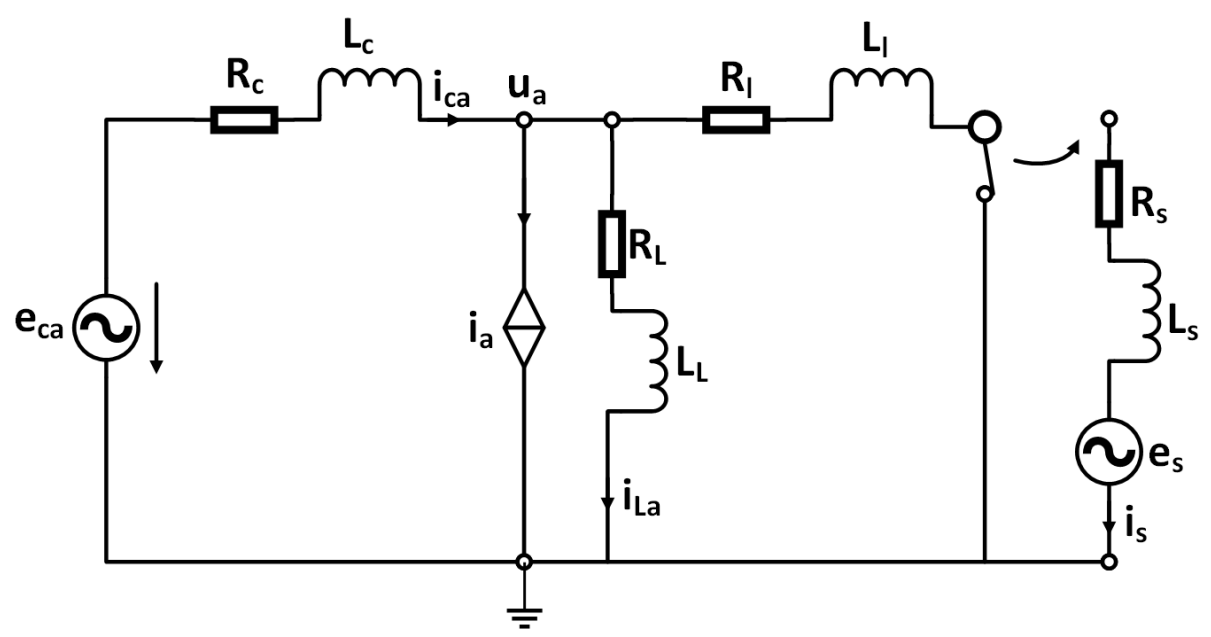

Figure 3. Single-phase equivalent circuit from control winding.

$$
e_{c a}(t)=U_{m} \cos (\omega t)
$$

Taking the Laplace transform of (4), we obtain $e_{\mathcal{c} a}$ in complex frequency domain as follows:

$$
e_{c a}(s)=\frac{U_{m} s}{s^{2}+\omega^{2}}
$$

Similarly, the current source representing the short circuit fault can be written in the frequency domain as:

$$
e_{s}(s)=\frac{U_{s} s}{s^{2}+\omega^{2}}
$$

where $U_{s}$ is the amplitude of the voltage after the short circuit fault. At natural speed, $i_{a}=0$ and under normal conditions, it can be assumed without loss of generality that the grid line impedance is negligible. In the presence of a short circuit fault, the switch in Figure 3 will be closed and the the stator control winding current can be written as:

$$
i_{c a}(s)=\frac{e_{c a}(s)-e_{s}(s)}{L s+R}=\frac{U}{(L s+R)\left(s^{2}+\omega^{2}\right)},
$$

where the total inductance $L$, total resistance $R$, and total voltage $U$ are given by

$$
\begin{aligned}
R & =R_{c}+R_{l}+R_{s} \\
L & =L_{c}+L_{L}+L_{l} \\
U & =U_{m}-U_{s} .
\end{aligned}
$$

Defining the magnitude and angle of the total impedance as follows:

$$
\begin{aligned}
|Z| & =\sqrt{R^{2}+(\omega L)^{2}} \\
\Phi & =\arctan \left(\frac{\omega L}{R}\right) .
\end{aligned}
$$

Then Equation (7) can be re-written as [20]:

$$
\begin{aligned}
i_{c a}(s) & =\frac{U}{|Z|^{2}}\left(\frac{R s}{s^{2}+\omega^{2}}+\frac{\omega^{2} L}{s^{2}+\omega^{2}}-\frac{R L}{L s+R}\right) \\
& =\frac{U}{|Z|}\left(\frac{s \cos \Phi}{s^{2}+\omega^{2}}+\frac{\omega \sin \Phi}{s^{2}+\omega^{2}}-\frac{\cos \Phi}{s+\frac{R}{L}}\right)
\end{aligned}
$$


Taking the inverse Laplace transform, we get:

$$
i_{c a}(t)=\frac{U}{|Z|} \cos (\omega t-\Phi)-\frac{U}{|Z|} \cos (-\Phi) e^{-\frac{R}{L} t}
$$

Equation (15) shows that the control winding current is composed of two components: first, a fundamental frequency component, and second, an exponentially decaying DC component. The equations for $b$ and $c$ phase currents of the stator control winding can be obtained similarly. Thus, the stator control winding current consists of a steady state component and transient component. The stator control winding current in the synchronous reference frame is obtained using Park transformation [28]:

$$
\begin{aligned}
i_{c d}(t) & =\frac{U}{|Z|} \cos \Phi-\frac{U}{|Z|} \cos (\omega t+\Phi) e^{-\frac{R}{L} t} \\
i_{c q}(t) & =\frac{U}{|Z|} \sin \Phi-\frac{U}{|Z|} \sin (\omega t+\Phi) e^{-\frac{R}{L} t}
\end{aligned}
$$

where the steady state and transient state components can be separated as follows:

$$
\begin{aligned}
i_{c d s} & =\frac{U}{|Z|} \cos \Phi, & i_{c d t}(t) & =-\frac{U}{|Z|} \cos (\omega t+\Phi) e^{-\frac{R}{L} t} \\
i_{c q s} & =\frac{U}{|Z|} \sin \Phi, & i_{c q t}(t) & =-\frac{U}{|Z|} \sin (\omega t+\Phi) e^{-\frac{R}{L} t}
\end{aligned}
$$

Thus, the active and reactive control winding currents are also composed of a DC steady state component and an exponentially decaying transient component. The synchronous reference frame voltages at the PCC are given by:

$$
\begin{aligned}
& u_{d}=e_{c d}-R_{c} i_{c d}-L_{c} \frac{d}{d t} i_{c d}-\omega L_{c} i_{c q} \\
& u_{q}=e_{c q}-R_{c} i_{c q}-L_{c} \frac{d}{d t} i_{c q}-\omega L_{c} i_{c d} .
\end{aligned}
$$

Therefore, the voltage drop at the PCC can now be obtained as:

$$
\begin{aligned}
& \Delta u_{d}=R_{c} i_{c d}+L_{c} \frac{d}{d t} i_{c d}+\omega L_{c} i_{c q} \\
& \Delta u_{q}=R_{c} i_{c q}+L_{c} \frac{d}{d t} i_{c q}+\omega L_{c} i_{c d} .
\end{aligned}
$$

Substituting Equations (16) and (17) into Equations (20) and (21) and simplifying, we obtain:

$$
\begin{aligned}
\Delta u_{d} & =\left(R_{c} i_{c d s}-\omega L_{c} i_{c q s}\right)+\frac{R_{c} L-L_{c} R}{L} i_{c d t} \\
\Delta u_{q} & =\left(R_{c} i_{c q s}-\omega L_{c} i_{c d s}\right)+\frac{R_{c} L-L_{c} R}{L} i_{c q t} .
\end{aligned}
$$

Note that the drop in the voltage magnitude at the PCC is a result of the steady state component, while the distortion at the PCC is caused by the transient component. However, during LVRT the focus is on reducing the magnitude of voltage drop to ride through the fault. Therefore, we can neglect the transient component, leading to

$$
\begin{aligned}
& \Delta u_{d}=\left(R_{c} i_{c d s}-\omega L_{c} i_{c q s}\right) \\
& \Delta u_{q}=\left(R_{c} i_{c q s}-\omega L_{c} i_{c d s}\right) .
\end{aligned}
$$

To obtain the a-phase voltage drop at the PCC $\Delta u_{a}$, substitute Equations (24) and (25) into the following Equation for the Park inverse transformation: 


$$
\begin{aligned}
\Delta u_{a} & =\Delta u_{d} \cos \omega t-\Delta u_{q} \sin \omega t \\
& =\sqrt{\left(R_{c} i_{c d s}-\omega L_{c} i_{c q s}\right)^{2}+\left(R_{c} i_{c q s}+\omega L_{c} i_{c d s}\right)^{2}} \cos (\omega t+\phi) \\
& =\sqrt{\left(R_{c}^{2}+\omega^{2} L_{c}^{2}\right)\left(i_{c d s}^{2}+i_{c q s}^{2}\right)} \cos (\omega t+\phi)
\end{aligned}
$$

where

$$
\phi=\arctan \frac{-R_{c} \omega L+\omega L_{c} R}{R_{c} R+\omega^{2} L_{c} L} .
$$

To find the q-axis current reference for reactive current compensation during a LVRT, we observe that the load current can be used to fully compensate reactive current corresponding the the short-circuit fault, i.e., $i_{q}^{*}=-i_{L q}$. This will lead to a zero reactive component in the stator control winding current, i.e., $i_{c q s}=0$. Then, we get from (28):

$$
\begin{aligned}
\Delta u_{a} & =\left|Z_{c}\right| i_{c d s} \cos (\omega t+\phi) \\
& =\left|Z_{c}\right| \frac{U}{|Z|} \cos \Phi \cos (\omega t+\phi),
\end{aligned}
$$

where

$$
\left|Z_{c}\right|=\sqrt{R_{c}^{2}+\omega^{2} L_{c}^{2}}
$$

and $\cos \Phi<1$. Thus, it can be observed that the voltage drop is minimized using $-i_{L q}$ as the reference current for reactive current compensation.

A block diagram depiction of the proposed controller is shown in Figure 4.

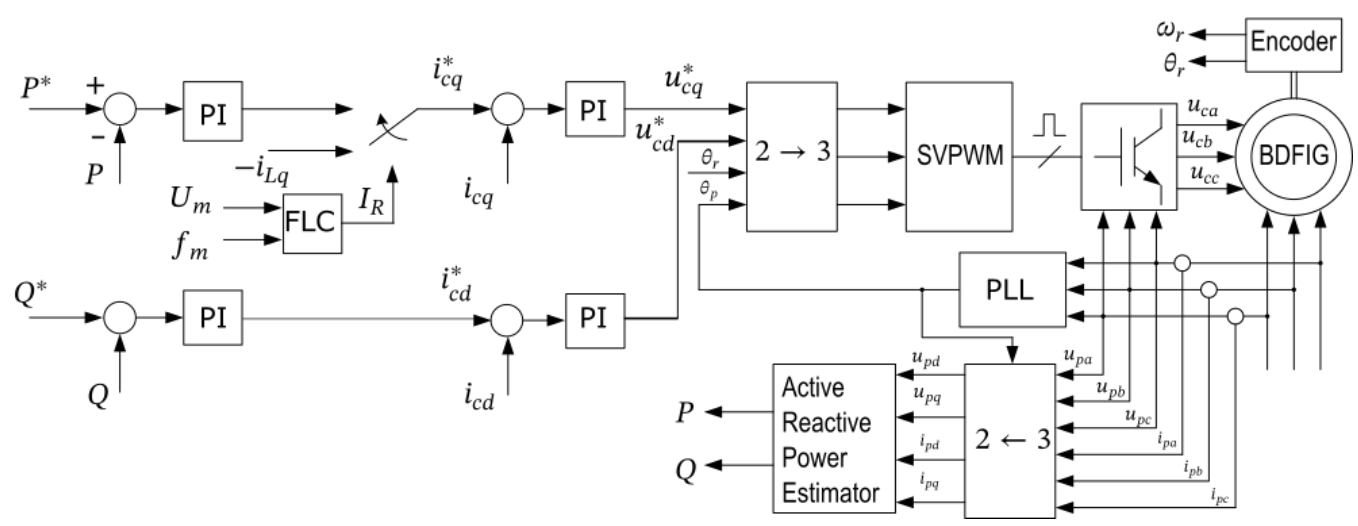

Figure 4. Rotor side converter controller.

\subsection{Fuzzy Logic Controller}

In this section we describe the proposed fuzzy logic controller which is responsible for activating the compensation modes of the rotor side converter controller depending on the situation.

\subsection{Fuzzification}

Our fuzzy logic controller uses two inputs, i.e., the instantaneous voltage $U_{m}$ and frequency $f_{m}$ at the PCC. The universe of discourse for these two inputs are [0 1$]$ and $\left[\begin{array}{ll}-6 & 6\end{array}\right]$, respectively. For $U_{m}, 0$ represents the rated value, while 1 represents the 0.2 p.u, i.e., the minimum voltage point for LVRT according to grid code requirements [29]. For $f_{m}$, a value of -6 corresponds to the minimum possible frequency, while, a value of 6 corresponds to the maximum possible frequency. The most commonly used membership functions in fuzzy logic are triangular, Gaussian, and Trapezoidal [30]. In this paper, based on numerical experiments [31], we chose triangular membership functions for $U_{m}$ and $f_{m}$ as shown in Figure 5. Four linguistic values: zero (ZO), positive small (PS), positive medium (PM), and positive big $(\mathrm{PB})$, are used for voltage, while seven seven linguistic 
values: negative big (NB), negative medium (NM), negative small (NS), zero (ZO), positive small (PS), positive medium (PM), and positive big (PB), are used for frequency.

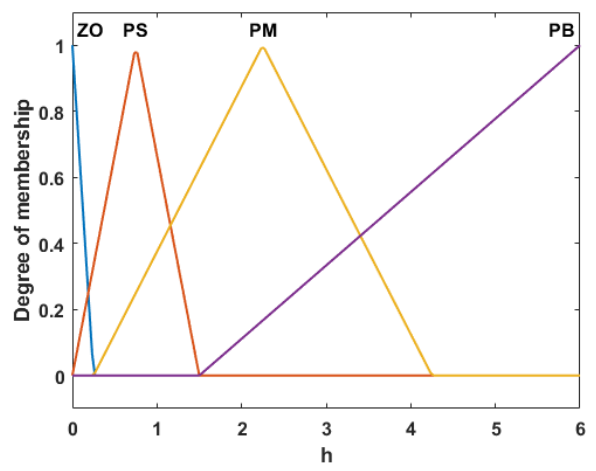

(a) $U_{m}$

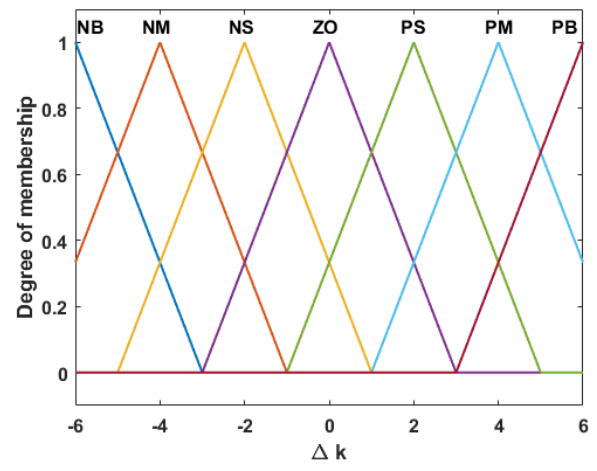

(b) $f_{m}$

Figure 5. Input membership functions.

The output of the proposed fuzzy logic controller is a binary value, which turns on the compensation mode of the rotor side converter in case of a fault or keeps it running in normal mode in the absence of a fault. Therefore, the proposed fuzzy logic controller has one output $I_{R}$ with the membership function shown in Figure 6. The output is represented by four linguistic values: zero (ZO), positive small (PS), positive medium (PM), and positive big (PB).

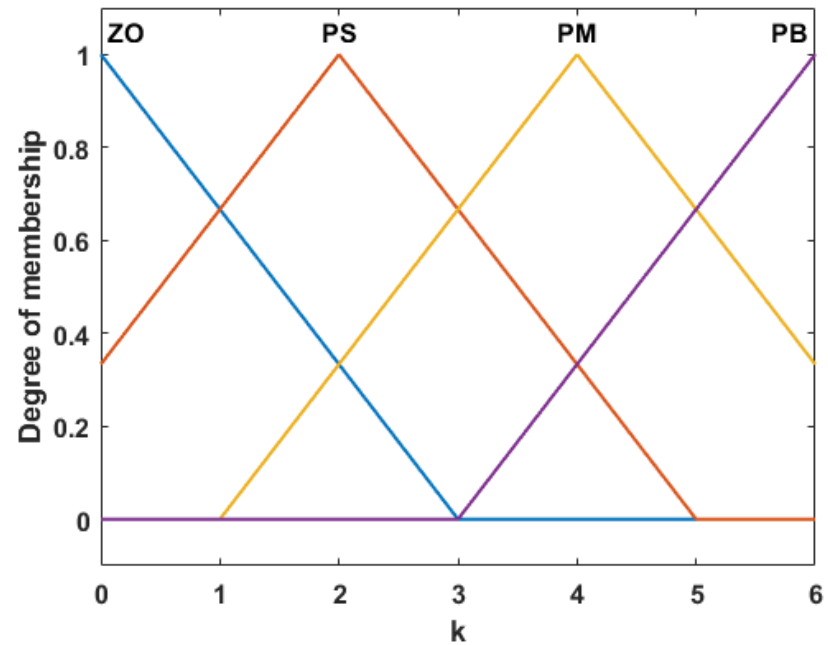

Figure 6. Output membership function: $I_{R}$.

\subsection{Knowledge Base}

To develop the knowledge base of the proposed fuzzy logic controller, we first observe the following:

1. If there is no voltage drop and no change in frequency, then the rotor side converter should run in normal mode.

2. If there is no voltage drop but the change in frequency is large then the compensation mode of rotor side converter should be turned on.

3. If the voltage drop is large and there is no change in frequency, then the compensation mode of rotor side converter should be turned on.

4. If the voltage drop is large and the frequency has changed, then the compensation mode of rotor side converter should be turned on.

Using a similar approach we obtain the rule base in Table 3. 
Table 3. Rule base for proposed fuzzy logic controller.

\begin{tabular}{cccccccc}
\hline Rule \# & $\boldsymbol{U}_{\boldsymbol{m}}$ & $f_{\boldsymbol{m}}$ & $\boldsymbol{I}_{\boldsymbol{R}}$ & Rule \# & $\boldsymbol{U}_{\boldsymbol{m}}$ & $f_{\boldsymbol{m}}$ & $\boldsymbol{I}_{\boldsymbol{R}}$ \\
\hline 1 & ZO & ZO & ZO & 9 & ZO & PM & NM \\
2 & PS & ZO & PS & 10 & PS & PM & NS \\
3 & PM & ZO & PM & 11 & PM & PM & ZO \\
4 & PB & ZO & PB & 12 & PB & PM & PS \\
5 & ZO & PS & NS & 13 & ZO & PB & NB \\
6 & PS & PS & ZO & 14 & PS & PB & NM \\
7 & PM & PS & PS & 15 & PM & PB & NS \\
8 & PB & PS & PM & 16 & PB & PB & ZO \\
\hline
\end{tabular}

\subsection{Inference Engine}

The inference engine combines the rules in the knowledge base to produce a control output. In this paper, we used the popular and most commonly used individual rule firing inference engine using Mamdani implications [32]. Each individual rule is fired by the inference engine and then using the minimum degree of membership of each input, the control output is computed. An example of individual rule firing via the Mamdani implication using min-inference is as follows:

- If $U_{m}$ is PS with grade 0.7467 and $f_{m}$ is $Z O$ with grade 1.0, then $I_{R}$ is PS with grade $0.7467=\min (0.7467,1.0)$.

- If $U_{m}$ is PM with grade 0.1550 and $f_{m}$ is $Z O$ with grade 1.0, then $I_{R}$ is PM with grade $0.1550=\min (0.1550,1.0)$.

\subsection{Defuzzification}

Once a fuzzy value for the control output is obtained, it needs to be converted into a crip value, i.e., in our case the outputs can have a value in $\left[\begin{array}{ll}0 & 1\end{array}\right]$ but we need to convert it into a binary value of 0 or 1 . For this purpose, we use the height method for defuzzification [31]. The action of converting fuzzy control actions into nonfuzzy (or crisp) ones is called defuzzification. For example, the consequences " $I_{r}$ is PS with grade 0.7467 " and " $I_{R}$ is PM with grade 0.1550 " cannot be used in practice. Thus, these consequences need to be converted into a crisp value, i.e., $I_{R}^{*} \in 0,1$. For this purpose, we used the most popular method for defuzzification called the height method. In this method, the peak value $e_{i}$ for each consequence is found using the output membership function and the membership grade value $f_{i}$ for each consequence. The crisp value for the output is calculated as follows:

$$
I_{R}^{*}=\frac{\sum_{i=1}^{k} e_{i} f_{i}}{\sum_{i=1}^{k} f_{i}} .
$$

Considering the above two consequences and the membership function given in Figure $6, e_{1}=2, e_{2}=4, f_{1}=0.7567$ and $f_{2}=0.1550$. Thus, the crisp value using (33) is as follows:

$$
I_{R}^{*}=\frac{2 \times 0.7567+4 \times 0.1550}{0.7567+0.1550}=2.34 \approx 2 .
$$

The next step is to normalize $I_{R}^{*}$ which gives us $\frac{I_{R}^{*}}{6}=0.33$. As the resulting value is less than 0.5 , the rotor side converter is run in normal mode. The rotor side converter's compensation mode is turned on if $\frac{I_{R}^{*}}{6} \geq 0.5$

\section{Results and Discussion}

In this section, we present results to evaluate the effectiveness of the proposed controller. We compare the performance of the proposed technique with the two of the most relevant and recent techniques proposed in Tohidi et al. [6] and Zhang et al. [17] using simulations in Matlab/Simulink. The simulation parameters are given in Table 4. A symmetric short circuit fault is introduced at time $2 \mathrm{~ms}$ and the fault is cleared at $3 \mathrm{~ms}$. 
Table 4. Simulation parameters.

\begin{tabular}{cc}
\hline Parameter & Value \\
\hline Rated Power & $40 \mathrm{kVA}$ \\
\hline Power factor & 0.8 \\
\hline Rated Stator power winding Voltage & $120 \mathrm{~V}$ \\
\hline Rated stator power winding current & $150 \mathrm{~A}$ \\
\hline Rated operating frequency & $50 \mathrm{~Hz}$ \\
\hline Switching frequency & $4 \mathrm{KHz}$ \\
\hline$p_{p}, p_{c}$ & 2,6 \\
\hline$\omega_{n}$ & 475 rpm \\
\hline$C_{d c}, u_{d c}$ & $0.01 \mathrm{~F}, 700 \mathrm{~V}$ \\
\hline$L_{s}, L_{p}, L_{c}, L_{r}$ & 0.214 p.u., 0.0715 p.u., 0.0122 p.u., 0.0133 p.u. \\
\hline$R_{p}, R_{c}, R_{r}$ & 0.017 p.u., 0.0108 p.u., 0.047 p.u. \\
\hline$L_{r p}, L_{r c}$ & 19.223 p.u., 5.035 p.u. \\
\hline
\end{tabular}

Figure 7 shows the power winding voltage before, during, and after the fault for the proposed technique, the technique proposed in Tohidi et al., and the technique proposed in Zhang et al. [17], respectively. It can be observed that using the proposed technique the minimum power winding voltage is 0.27 p.u. while that for Tohidi et al. [6] and Zhang et al. [17] is 0.15 and 0.16 p.u., respectively. Moreover, after the fault is cleared, the voltage transients using the proposed technique are significantly reduced. This is due to two reasons, first, the fuzzy logic controller manages to turn off the compensation mode when the voltage starts to improve after fault clearing, and second, the reference value derived from the mathematical model results in better stability.

The power winding current for the proposed technique is shown in Figure 8 and that for the techniques proposed in Tohidi et al. [6] and Zhang et al. [17] is shown in Figure 9. We observe that although all techniques manage to reduce the power winding current, the power winding current using the techniques proposed in Zhang et al. and Tohidi et al. is not only significantly reduced with a risk of disconnection but also has a higher harmonic content during the transient period. The THD of the power winding current using the proposed technique during the transient period is $22.5 \%$ while that of Tohidi et al. and Zhang et al. is $36.2 \%$ and $34.5 \%$.

To observe the effect of the proposed technique during the fault, Figures 10 and 11 present the power winding current in the synchronous reference frame. It can be observed that the proposed technique not only results in significantly smaller transients but also results in lesser oscillations. 


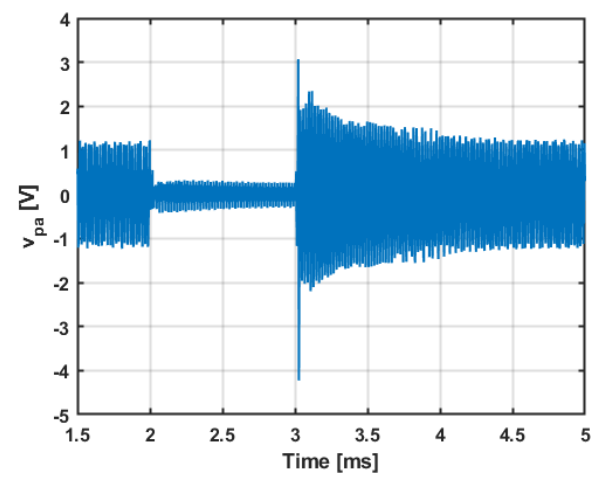

(a) power winding Voltage- - proposed.

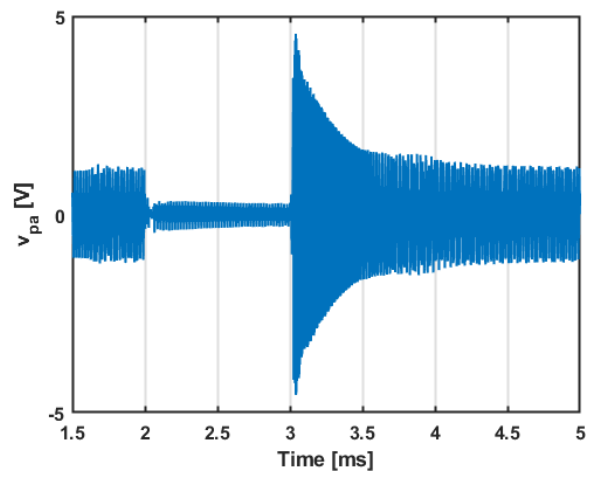

(c) power winding Voltage-Zhang et al.

Figure 7. Power winding voltage.

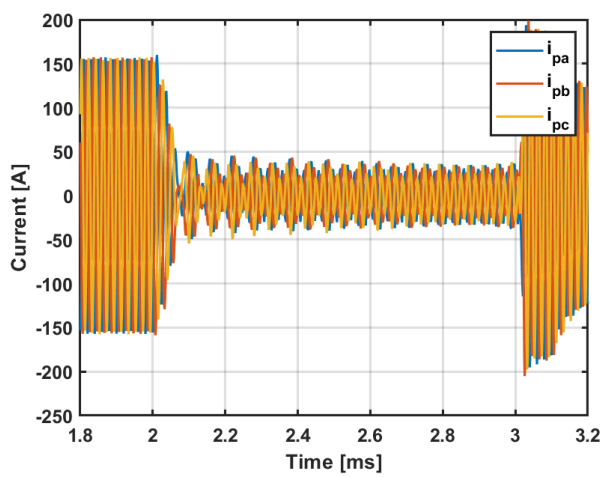

(a) power winding Current-proposed.

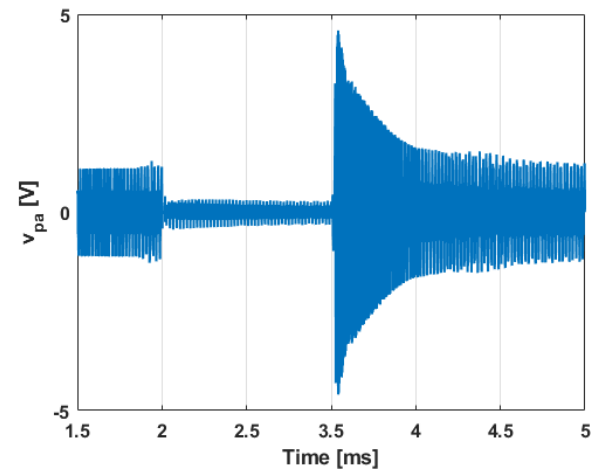

(b) power winding Voltage-Tohidi et al.

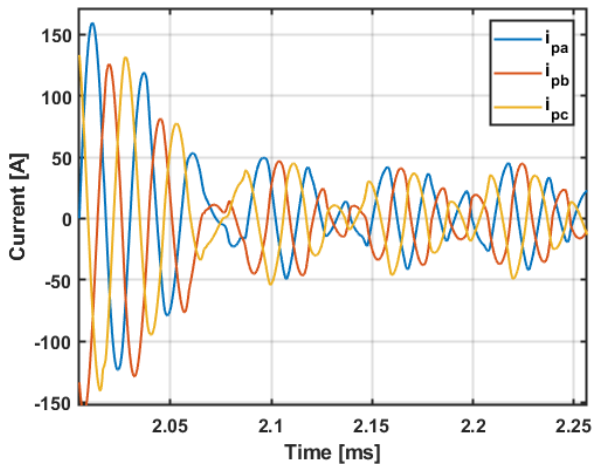

(b) power winding Current (Zoomed)-proposed.

Figure 8. Power winding Current-proposed. 


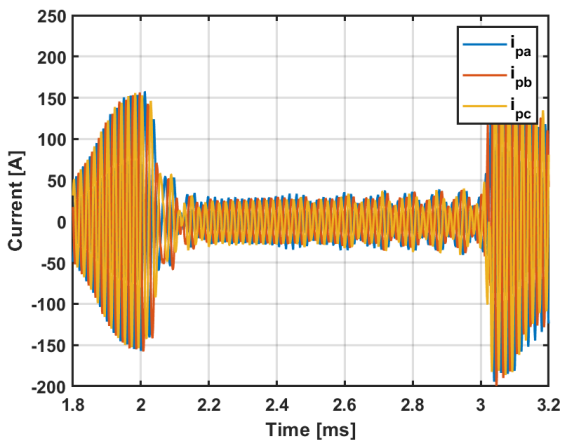

(a) power winding Current-Tohidi et al

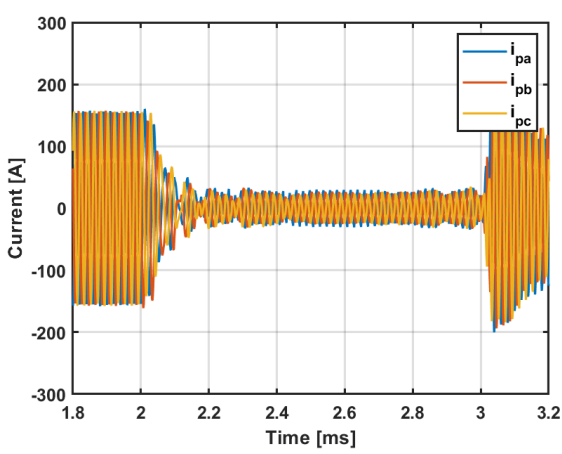

(c) power winding Current-Zhang et al

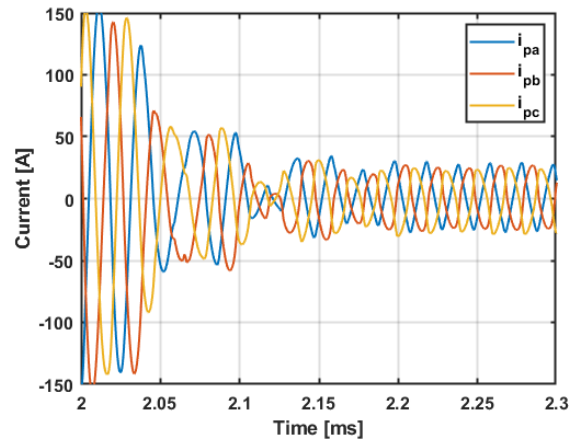

(b) power winding Current (Zoomed)-Tohidi et al.

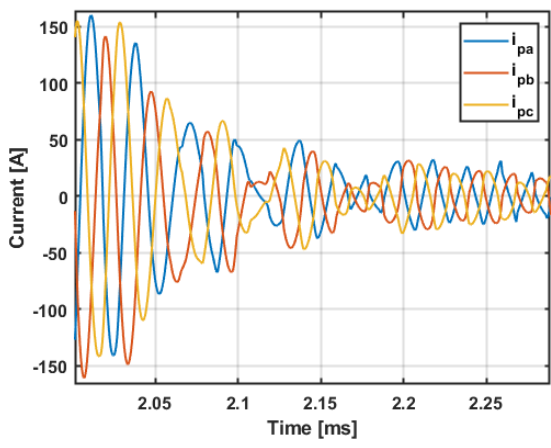

(d) power winding Current (Zoomed)-Zhang et al.

Figure 9. Power winding Current—existing techniques.

When a fault occurs, the brushless doubly-fed induction generator needs to provide reactive power instead of consuming it. Moreover, during a fault, the outer loop is disconnected so the active power production is reduced to almost a halt. This is shown in Figure 12. We observe from Figure 12a that the proposed technique successfully injects reactive power into the grid during the fault while the active power produced is reduced to near zero. We also observe that the techniques proposed in Tohidi et al. [6] and Zhang et al. [17] exhibit a similar behavior. However, the oscillations in Figure 12 are significantly more than the proposed technique. Moreover, the proposed technique converges to the optimal value of reactive current at time $2.167 \mathrm{~ms}$ as opposed to 2.340 and $2.272 \mathrm{~ms}$ for the techniques proposed in Tohidi et al. [6] and Zhang et al. [17], respectively. Thus, the proposed technique results in a faster response thanks to the fuzzy logic controller.

Table 5 summarizes how our proposed method squares with Tohidi et al. and Zhang et al. The improvement indicated by the three parameters, namely, the total harmonic distortion (THD), the settling time, and the number of cycles before entering the band of amplitude 50 , is significant. 


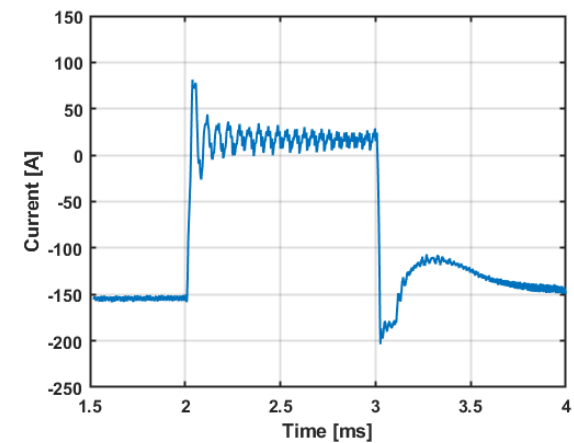

(a) power winding d Current-proposed.

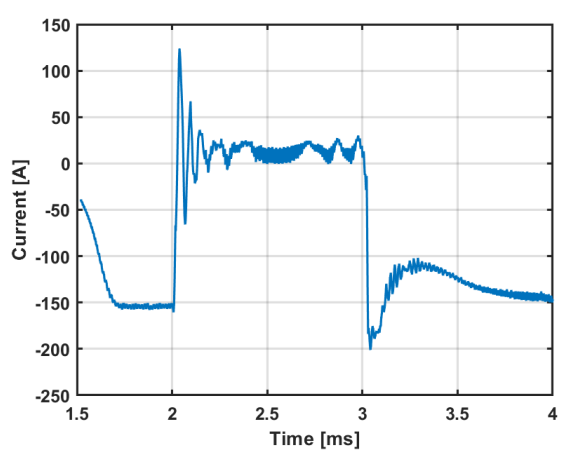

(c) power winding d Current-Zhang et al.

Figure 10. Power winding Current in Synchronous Reference Frame-d-component

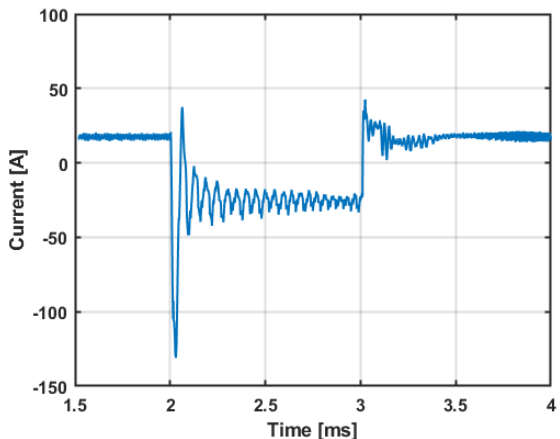

(a) power winding q Current-proposed.

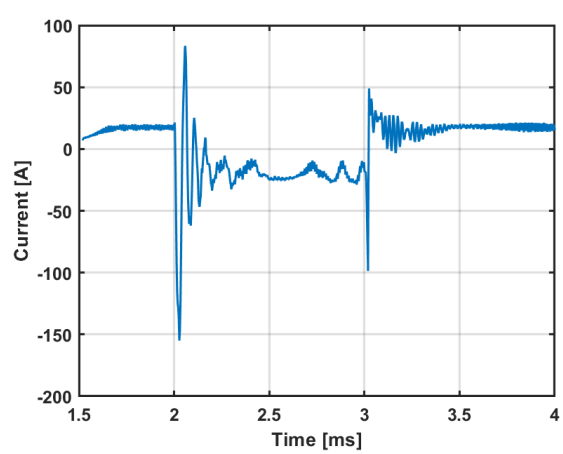

(c) power winding q Current-Zhang et al.

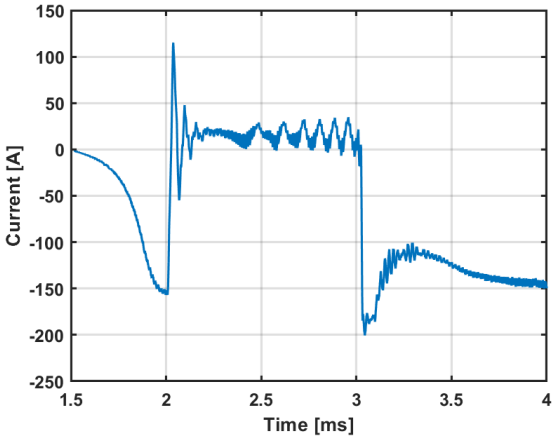

(b) power winding d Current-Tohidi et al.

Figure 11. Power winding Current in Synchronous Reference Frame-q-component. 


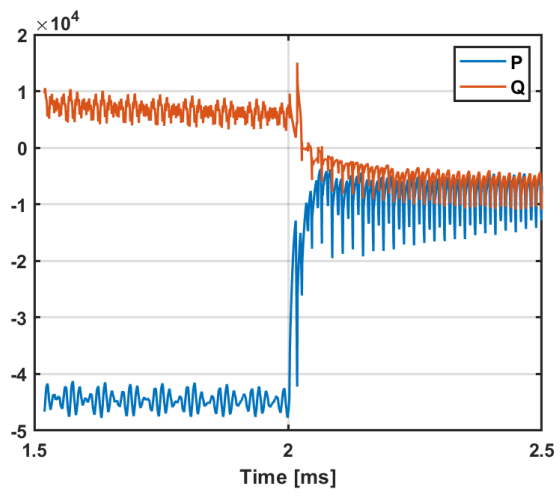

(a) Active \& Reactive Power-proposed.

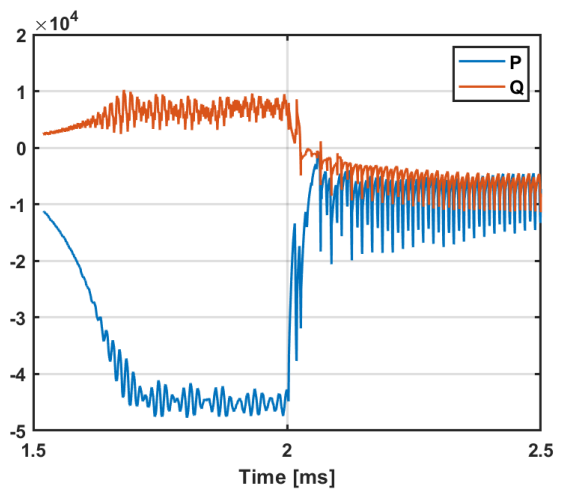

(c) Active \& Reactive Power-Zhang et al.

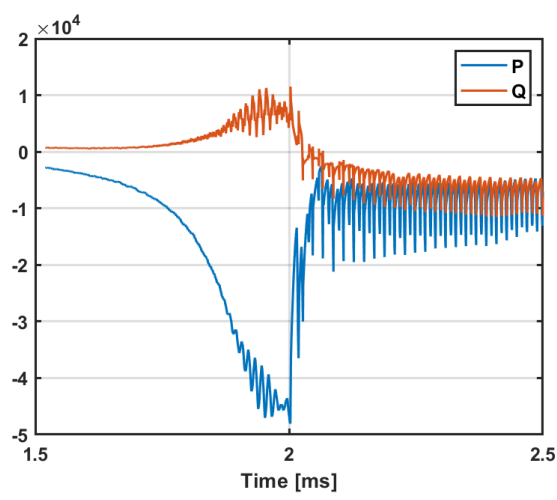

(b) Active \& Reactive Power-Tohidi et al.

Figure 12. Power.

Table 5. Summary of comparison.

\begin{tabular}{cccc}
\hline & THD & Settling Time & Voltage-Drop \\
\hline Tohidi et al. & $36.2 \%$ & $2.340 \mathrm{~ms}$ & 0.85 p.u. \\
\hline Zhang et al. & $34.5 \%$ & $2.272 \mathrm{~ms}$ & 0.84 p.u. \\
\hline Proposed & $22.5 \%$ & $2.167 \mathrm{~ms}$ & 0.73 p.u. \\
\hline $\begin{array}{c}\text { Minimum } \\
\text { Improvement }\end{array}$ & $\mathbf{1 2 \%}$ & $\mathbf{0 . 1 0 5} \mathbf{~ m s}$ & $\mathbf{0 . 1 1}$ p.u. \\
\hline
\end{tabular}

\section{Conclusions}

This paper presented a reactive current control technique for the rotor side converter of a brushless doubly-fed induction generator to reduce the PCC voltage drop in case of short circuit faults leading to better LVRT characteristics of the machine. The brushless doubly-fed induction generator is represented by an equivalent circuit and the single phase equivalent circuit seen from the rotor side converter is used to analyze the steady state components of the voltage drop at the PCC. By analyzing the voltage drop at the PCC using the q-axis load current as the reference, the voltage drop is minimized. To quickly detect the onset of a LVRT in case of a fault condition, a fuzzy logic controller was proposed using the power winding voltage magnitude and frequency as inputs. The proposed controller was thoroughly evaluated using simulations in Matlab/Simulink. The results show that the proposed technique can reduce the voltage drop by up to 0.12 p.u. and also reduce the transients.

The proposed technique considers only the steady state component of the load current to reduce the voltage drop at PCC during faults. However, to reduce the oscillations during the fault, the proposed technique can be extended to include the transient component 
of load current. Although the use of a fuzzy logic controller improves the rotor side converter's response to a fault, the proposed technique is sensitive to the rules in the knowledge base. Therefore, the knowledge base needs to be designed carefully to avoid sub-optimal results.

Author Contributions: Conceptualization, A.M., M.W.M. and M.N.A.; Methodology, A.M., M.N.A., M.U. and A.H.; Supervision, M.W.M. and M.N.A.; Validation, A.M., T.K. and M.U.; Visualization, A.M. and M.U.; Writing original draft, A.M. and A.H.; Writing review editing, M.W.M., M.N.A. and A.H. All authors have read and agreed to the published version of the manuscript.

Funding: This research received no external funding.

Institutional Review Board Statement: Not applicable.

Informed Consent Statement: Not applicable.

Data Availability Statement: Not applicable to the manuscript.

Acknowledgments: The authors would like to acknowledge the facilities provided by Universiti Teknologi Malaysia for the accomplishment of this work. Furthermore, the authors greatly acknowledge the support by Higher Education Commission of Pakistan.

Conflicts of Interest: The authors declare no conflict of interest.

\section{References}

1. Mohammed, O.O.; Mustafa, M.W.; Aman, M.N.; Salisu, S.; Otuoze, A.O. Capacity benefit margin assessment in the presence of renewable energy. Int. Trans. Electr. Energy Syst. 2020, 30, etep12502. [CrossRef]

2. Mohammed, O.O.; Mustafa, M.W.; Aman, M.N. A Graph-Theoretic Approach to Capacity Benefit Margin Calculation for Large Multiarea Power Systems. IEEE Syst. J. 2020, 14, 1230-1233. [CrossRef]

3. Moazen, M.; Kazemzadeh, R.; Azizian, M.R. Model-based predictive direct power control of brushless doubly fed reluctance generator for wind power applications. Alex. Eng. J. 2016, 55, 2497-2507. [CrossRef]

4. Larik, R.M.; Mustafa, M.W.; Aman, M.N.; Jumani, T.A.; Sajid, S.; Panjwani, M.K. An Improved Algorithm for Optimal Load Shedding in Power Systems. Energies 2018, 11, 180 . [CrossRef]

5. Larik, R.M.; Mustafa, M.W.; Aman, M.N. A critical review of the state-of-art schemes for under voltage load shedding. Int. Trans. Electr. Energy Syst. 2019, 29, e2828. [CrossRef]

6. Tohidi, S.; Oraee, H.; Zolghadri, M.R.; Shao, S.; Tavner, P. Analysis and enhancement of low-voltage ride-through capability of brushless doubly fed induction generator. IEEE Trans. Ind. Electron. 2013, 60, 1146-1155. [CrossRef]

7. Tohidi, S.; Abdi, E.; Shao, S.; Zolghadri, M.; McMahon, R.; Tavner, P.; Oraee, H. Low voltage ride-through of DFIG and brushless DFIG: Similarities and differences. Electr. Power Syst. Res. 2014, 110, 64-72. [CrossRef]

8. Gholizadeh, M.; Tohidi, S.; Oraee, A.; Oraee, H. Appropriate crowbar protection for improvement of brushless DFIG LVRT during asymmetrical voltage dips. Int. J. Electr. Power Energy Syst. 2018, 95, 1-10. [CrossRef]

9. Döşoğlu, M.K. Crowbar hardware design enhancement for fault ride through capability in doubly fed induction generator-based wind turbines. ISA Trans. 2020, 104, 321-328. [CrossRef]

10. Das, J.C. Effects of harmonics. In Power System Harmonics and Passive Filter Designs; John Wiley \& Sons: Hoboken, NJ, USA, 2015; pp. 331-378.

11. Shao, S.; Long, T.; Abdi, E.; Mcmahon, R.A. Dynamic Control of the Brushless Doubly Fed Induction Generator Under Unbalanced Operation. IEEE Trans. Ind. Electron. 2013, 60, 2465-2476. [CrossRef]

12. Long, T.; Shao, S.; Abdi, E.; McMahon, R.A.; Liu, S. Asymmetrical low-voltage ride through of brushless doubly fed induction generators for the wind power generation. IEEE Trans. Energy Convers. 2013, 28, 502-511. [CrossRef]

13. Long, T.; Shao, S.; Malliband, P.; Abdi, E.; McMahon, R.A. Crowbarless fault ride-through of the brushless doubly fed induction generator in a wind turbine under symmetrical voltage dips. IEEE Trans. Ind. Electron. 2013, 60, 2833-2841. [CrossRef]

14. Tohidi, S.; Oraee, H.; Zolghadri, M.R.; Rahimi, M. A control scheme to enhance low voltage ride-through of brushless doubly-fed induction generators. Wind Energy 2016, 19, 1699-1712. [CrossRef]

15. Huang, J.; Li, S. Analytical expression for LVRT of BDFIG with enhanced current control to CW and reactive power support from GSC. Int. J. Electr. Power Energy Syst. 2018, 98, 243-255. [CrossRef]

16. Hang, C.; Wang, X.; Liu, N.; Kong, M.; Nie, P.; Li, Z. Virtual inductance control strategy for brushless doubly-fed induction generator during grid voltage dips. In Proceedings of the 2018 21st International Conference on Electrical Machines and Systems (ICEMS), Jeju, Korea, 7-10 October 2018; pp. 1533-1537.

17. Zhang, A.; Chen, Z.; Gao, R.; Wang, J.; Ma, Z.; Wang, S.; Wang, Y. Crowbarless Symmetrical Low-Voltage Ride Through Based on Flux Linkage Tracking For Brushless Doubly Fed Induction Generators. IEEE Trans. Ind. Electron. 2020, 67, 7606-7616. [CrossRef] 
18. Lu, M.; Chen, Y.; Zhang, D.; Su, J.; Kang, Y. Virtual Synchronous Control Based on Control Winding Orientation for Brushless Doubly Fed Induction Generator (BDFIG) Wind Turbines Under Symmetrical Grid Faults. Energies 2019, 12, 319. [CrossRef]

19. Shao, S.; Long, T.; Abdi, E.; McMahon, R.; Wu, Y. Symmetrical low voltage ride-through of the brushless doubly-fed induction generator. In Proceedings of the IECON 2011-37th Annual Conference of the IEEE Industrial Electronics Society, Melbourne, Australia, 7-10 November 2011; pp. 3209-3214. [CrossRef]

20. Wang, X.; Lin, H.; Wang, Z. Transient Control of the Reactive Current for the Line-Side Converter of the Brushless Doubly-Fed Induction Generator in Stand-Alone Operation. IEEE Trans. Power Electron. 2017, 32, 8193-8203. [CrossRef]

21. Zhang, R.; Phillis, Y.A.; Kouikoglou, V.S. Fuzzy Control of Queuing Systems; Springer: London, UK, 2005; pp. 1-175.

22. Altas, I.H. Fuzzy Logic Control in Energy Systems with Design Applications in MATLAB®/Simulink®; The Institute of Engineering \& Technology: London, UK, 2017. [CrossRef]

23. Sadeghi, R.; Madani, S.M.; Ataei, M. A New Smooth Synchronization of Brushless Doubly-Fed Induction Generator by Applying a Proposed Machine Model. IEEE Trans. Sustain. Energy 2018, 9, 371-380. [CrossRef]

24. Perelmuter, V. Simulation with Sumulink and SimPowerSystems. In Renewable Energy Systems; CRC Press: Boca Raton, FL, USA, 2017.

25. Zhang, J.; Ding, H.; Wang, B.; Guo, X.; Padmanaban, S. Active Power Decoupling for Current Source Converters: An Overview Scenario. Electronics 2019, 8, 197 [CrossRef]

26. Memon, A.; Mustafa, M.W.; Aman, M.N.; Hafeez, A.; Ullah, M. Improving Transient Behavior of a Brushless Doubly Fed Induction Generator through Reactive Current Control of Grid-Side Converter. Electronics 2021, 10, 1413. [CrossRef]

27. Qoria, T.; Guillaud, X. Chapter 8-Control of power electronics-driven power sources. In Converter-Based Dynamics and Control of Modern Power Systems; Monti, A., Milano, F., Bompard, E., Guillaud, X., Eds.; Academic Press: Cambridge, MA, USA, 2021; pp. 193-234. [CrossRef]

28. Khidrani, A.; Habibuddin, M.H.; Mustafa, M.W.; Aman, M.N.; Mokhtar, A.S. A hybrid voltage-current compensator using a synchronous reference frame technique for grid-connected microgrid under nonlinear load conditions. Int. Trans. Electr. Energy Syst. 2020, 30, e12530. [CrossRef]

29. Nhlapo, B.; Awodele, K. Review and comparison of the South African grid code requirements for wind generation with the European countries' grid codes. In Proceedings of the 2020 International SAUPEC/RobMech/PRASA Conference, Cape Town, South Africa, 29-31 January 2020; pp. 1-6.

30. Ross, T. Fuzzy Logic with Engineering Applications; Wiley: Hoboken, NJ, USA, 2010. [CrossRef]

31. Ofoli, A.R. 36-Fuzzy-logic applications in electric drives and power electronics. In Power Electronics Handbook, 4th ed.; Rashid, M.H., Ed.; Butterworth-Heinemann: Oxford, UK, 2018; pp. 1221-1243.

32. Shahbazova, S.N.; Sugeno, M.; Kacprzyk, J. Recent Developments in Fuzzy Logic and Fuzzy Sets; Studies in Fuzziness and Soft Computing; Springer Nature Switzerland: Cham, Switzerlan, 2020. 